\title{
ALCOHOL IN ITS RELATION TO VENEREAL DISEASE.
}

\section{BY MRS. MARY SGHARLIEB, M.D., M.S.,}

A Member of the Royal Commission on Venereal Disease; ex-President of the Society for the Study of Inebriety; Consulting Physician, Royal Free Hospital, London; late Lecturer on Midwifery, London School of Medicine for Women; Author of "The Seven Ages of Woman," "What it Means to Marry," etc.

ON March 1, 1916, the Royal Commission on Venereal Diseases published its Final Report.* This Report embodies the result of a large amount of evidence gathered from many witnesses, and is certainly one of the most important documents dealing. with Public Health that has ever been published. The portion of it that most immediately concerns the Society for the Study of Inebriety is the short paragraph, No. 99, which deals with the relation between alcohol and venereal diseases. It commences with the statement that "abundant evidence was given as to the intimate relation between alcohol and venereal diseases," and it goes on to enumerate the reasons on which this opinion was based. It appeared from the evidence of Professor F. W. Mott, Dr. D. White, and Sir Victor Horsley, that alcohol renders a man peculiarly liable to yield to temptations which he might otherwise resist. The truth of this assertion is well known to all doctors from the sad experiences of their patients. Very frequently an unfortunate girl who comes to hospital infected with syphilis or gonorrhoea confesses that her misfortunes are due to the unaccustomed glass of wine that was offered to her by a so-called "friend" on a Bank Holiday or festive occasion. To the adolescent, unaccustomed to alcohol in any form, even one glass of intoxicating drink of such quality as is usually bought

* The Final Report of the Royal Commission on Venereal Diseases can be purchased through any bookseller, or from Messrs. Wyman and Sons, Ltd., 29, Bream's Buildings, Fetter Lane, London, E.C. The two volumes of Evidence are published separately. 
under the circumstances, may, in addition to sexual and other excitement, suffice to cause such a clouding of the judgment and such a weakening of self-control as to lead to acquiescence in deeds that would have been spurned by her when she was mistress of herself.

Not only does the influence of alcohol render the individual more liable to contract venereal disease by the throwing down of protective moral barriers, but it also makes the treatment both of syphilis and of gonorrhoea much more difficult, and most doctors insist that their patients shall be total abstainers, at any rate until the disease is cured. In the case of gonorrhoea the outward manifestations of the disease not infrequently become quiescent under suitable treatment; but they reappear with renewed intensity under the influence of certain stimuli, and of these those arising from the action of alcohol are among the most potent; indeed, Sir Thomas Barlow, in his evidence before the Commission, deposed that when he was physician at the Fever Hospital, and young men were brought in suffering from measles and scarlet fever, they constantly begged that no alcohol might be given to them, knowing only too well from past experience that it aggravated the symptoms of gonorrhoea. And further, he said, "From the very outset right on to the bitter end, the maleficent effect of alcohol on all venereal disease is remarkable." He was also of opinion "that the increasing sobriety among the population of all classes is another factor that may help in the diminution of these diseases."

Among the greatest blessings that science has conferred on the human race is the discovery that certain arseno-benzol compounds, such as salvarsan, gallyl, and karsivan, especially when used alternately with courses of mercurial inunction, are able both to cure syphilis and also very rapidly to render the sufferer non-infectious. The use of these potent drugs has in a very small percentage of cases caused alarming symptoms, but seldom or never in the case of a person who is organically sound. Sir Thomas Barlow in his evidence mentioned that, " in fact, Professor Ehrlich told me that some of the bad cases of damage done by salvarsan have been in alcoholic subjects, and Professor Ehrlich explicitly besought those who are carrying out the treatment on no consideration to use it on an alcoholic person." $\mathrm{He}$ added: "The way in which alcoholism shows up syphilitic lesions is one of the common-places of pathology. Everybody knows 
it makes syphilis more damaging and more refractory in every way from first to last. Again, it is very striking how, if you stop a man's alcohol when you are treating him for syphilis, and stop it absolutely, you often have so much more satisfactory results. There cannot be two opinions about that."

Dr. F. W. Mott, who has had very extensive experience of the influence of syphilis in causing general paralysis of the insane and certain other forms of insanity, said in his evidence "that a person who has syphilis of the nervous system has an invalid brain, and if he drinks he will certainly suffer seriously from it." He also showed that alcoholism plays a very important part in connection with aggravating the disease. He explained this statement by saying that, inasmuch as alcohol lowers the vitality of the tissues, it allows the micro-organism of syphilis a better chance of growth.

The evidence of Dr. Douglas White was very clear and emphatic with regard to the effect of alcohol in encouraging the infection of men and women with venereal disease. He said that " the doctors, who have made inquiries in thousands of cases, both abroad, in America, and here also, have informed us that about 80 per cent. of the men who acquire these diseases have told them that they have done so under the influence of some kind of alcohol." In reply to a question by the Chairman, he stated that in the case of the army the decrease of alcoholism has been of assistance in diminishing the prevalence of venereal diseases.

Sir Victor Horsley was equally emphatic in his evidence, and stated that "undoubtedly alcohol aggravates the disease by diminishing the resistance of the individual, as it does with all infective diseases. This has been especially drawn attention to in relation to the later manifestations of syphilis of the nervous system, such as general paralysis of the insane; and as prostitution is directly associated with the drink trade, and the drink trade is responsible for a great deal of prostitution, it follows that the people who are disseminating the disease have their own personal resistance to it greatly diminished."

From all this evidence we are justified in believing that alcoholism has a direct and injurious influence both in furthering the infection of the people with venereal diseases and also in rendering their treatment more difficult and their cure less 
probable. The evidence given before the Commission and the conclusions of the Commissioners lead us irresistibly to the belief that the avoidance of infection, the best hope of individual cure, and the prospect of stamping out this national danger, depend very largely on the intelligent care with which we seek the amelioration of the physical condition of the population and the promotion of self-control and temperance in all ways, but especially with reference to alcohol. 